\title{
The effectiveness of prescription drug monitoring programs at reducing opioid-related harms and consequences: a systematic review
}

\author{
Emily Rhodes', Maria Wilson ${ }^{1}$, Alysia Robinson ${ }^{1}$, Jill A. Hayden ${ }^{1}$ and Mark Asbridge ${ }^{1,2^{*}}$
}

\begin{abstract}
Background: In order to address the opioid crisis in North America, many regions have adopted preventative strategies, such as prescription drug monitoring programs (PDMPs). PDMPs aim to increase patient safety by certifying that opioids are prescribed in appropriate quantities. We aimed to synthesize the literature on changes in opioid-related harms and consequences, an important measure of PDMP effectiveness.

Methods: We completed a systematic review. We conducted a narrative synthesis of opioid-related harms and consequences from PDMP implementation. Outcomes were grouped into categories by theme: opioid dependence, opioid-related care outcomes, opioid-related adverse events, and opioid-related legal and crime outcomes.

Results: We included a total of 22 studies (49 PDMPs) in our review. Two studies reported on illicit and problematic use but found no significant associations with PDMP status. Eight studies examined the association between PDMP status and opioid-related care outcomes, of which two found that treatment admissions for prescriptions opioids were lower in states with PDMP programs $(p<0.05)$. Of the thirteen studies that reported on opioid-related adverse events, two found significant $(p<0.001$ and $p<0.05)$ but conflicting results with one finding a decrease in opioid-related overdose deaths after PDMP implementation and the other an increase. Lastly, two studies found no statistically significant association between PDMP status and opioid-related legal and crime outcomes (crime rates, identification of potential dealers, and diversion).

Conclusion: Our study found limited evidence to support overall associations between PDMPs and reductions in opioid-related consequences. However, this should not detract from the value of PDMPs' larger role of improving opioid prescribing.
\end{abstract}

Keywords: Prescription drug monitoring programs, Opioids, Harms, Consequences

\section{Background}

The misuse of opioids has reached epidemic levels across North America [1]. The crisis has been perpetuated, in part, by the over and inappropriate prescribing of opioids by health professionals, brought on by improvements in the treatment of chronic pain and pharmaceutical companies' push to use opioids as a first

\footnotetext{
* Correspondence: mark.asbridge@dal.ca

'Department of Community Health \& Epidemiology, Dalhousie University, Halifax, NS, Canada

${ }^{2}$ Department of Emergency Medicine, Dalhousie University, Halifax, NS, Canada
}

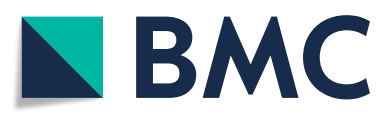

(c) The Author(s). 2019 Open Access This article is distributed under the terms of the Creative Commons Attribution 4.0 International License (http://creativecommons.org/licenses/by/4.0/), which permits unrestricted use, distribution, and reproduction in any medium, provided you give appropriate credit to the original author(s) and the source, provide a link to the Creative Commons license, and indicate if changes were made. The Creative Commons Public Domain Dedication waiver (http://creativecommons.org/publicdomain/zero/1.0/) applies to the data made available in this article, unless otherwise stated. people have a severe opioid use disorder (OUD), which involves dependence on opioid analgesic medications, heroin, or both [1,4]. The increasing use of opioids has led to many consequences such as more frequent incidents of reported opioid misuse, drug diversion, crime, overdoses, and death [5-11].

In order to address the opioid crisis many regions have adopted preventative initiatives, including physician mentoring, continuing medical education on pain management, naloxone kits, and, the focus of the current study, prescription drug monitoring programs (PDMPs) 
[12-17]. PDMPs facilitate controlled substances like opioids to be prescribed in appropriate quantities, following best practice guidelines, not co-prescribed with potentially harmful substances, and only provided to patients when safe and necessary [14]. This is achieved by monitoring the prescribing practices of healthcare providers and identifying any patterns of drugs received by patients. Most PDMPs give healthcare providers the option to check PDMP data (patient profiles) before prescribing or dispensing opioids to a patient, allowing for more informed decision making. Broadly, PDMPs aim to restrict drug diversion and reduce opioid misuse-related harms $[18,19]$.

As of 2018, 49 states, the District of Columbia, and two U.S. territories (Guam \& Puerto Rico) had implemented a PDMP [20]. A 2009 report estimated that start-up costs of a PDMP in the United States ranged between $\$ 450,000$ and $\$ 1.5$ million, with an average annual cost of $\$ 500,000$ for maintaining a PDMP [21]. Significant resources are directed to these programs on an ongoing basis, and, as such, there is a need to evaluate their effectiveness.

An important measure of PDMP effectiveness is a reduction in opioid-related harms and consequences [22]. A 2018 scoping review addressed the association of PDMPs with fatal and non-fatal overdoses for any drugs [23]. This review found uncertainty in the evidence around an increase or decrease in fatal and nonfatal overdoes after the implementation of PDMPs [23]. However, individual studies on PDMP effectiveness report a broad range of other opioid-related outcomes, including dependence, emergency department (ED) visits, crime, treatment admissions, and illicit opioid use [24-28].

To date, no systematic review has been undertaken to synthesize the evidence on the impact of PDMPs on a range of opioid-related outcomes of interest to health professionals, decision-makers and other knowledge users, including associated harms and consequences. Understanding whether these programs work as intended is a crucial piece of information to combat the current opioid crisis.

\section{Methods}

\section{Eligibility criteria}

We included full published reports in all languages. Study designs were restricted to those that could draw conclusions on the effectiveness of PDMPs in reducing opioid-related consequences and harms (pre-post studies, controlled before/after, case-control, or cluster RCT designs). Two reviewers independently selected relevant studies from titles and abstracts. Any conflicts at the title and abstract level were discussed between the two reviewers. If consensus could not be achieved after discussion, the study was carried forward to the full-text screening level. Any conflicts at the full-text screening level were resolved by consulting with a third reviewer. We used Covidence software for all study screening [29]. Covidence, an online systematic review management platform, is a key element of Cochrane's review production toolkit that facilitates study screening and data extraction.

We included studies of any jurisdiction (regional, provincial/state, national) or setting (clinic, hospital, system) where a PDMP had been implemented and where either a within jurisdiction comparison was made (pre- postPDMP implementation) or a between jurisdiction comparison was made between those with and without a PDMP. We did not restrict studies by geographic region.

\section{Reporting the intervention}

We considered the intervention of interest the presence of a PDMP, defined as a program that specifically monitors the outpatient prescription dispensing of opioids (or other drugs) by healthcare providers. To ensure broad scope of our review, we included all types of PDMPs.

\section{Outcomes of interest}

We included opioid-related outcomes only in this review. It is important to note that we did not limit these outcomes to those related to prescription opioid use. We also included outcomes related to illicit opioids such as heroin, as the literature suggests that there is the potential for PDMPs to push people who use prescription opioids to illicit sources [6]. We did not include outcomes that addressed non-opioid analgesics, and other controlled substances monitored by PDMPs (e.g. benzodiazepines).

Opioid-related consequences and harms were grouped into categories by theme: opioid dependence (i.e. substance use disorders), opioid-related care outcomes (i.e. hospital visits, treatment program admissions), opioidrelated adverse events (i.e. overdose, death), and opioidrelated legal and criminal outcomes (i.e. arrests, diversion). Use and consequence outcomes could be linked to all opioids, or to specific types of opioids.

\section{Search strategy}

We followed a standard systematic review approach, employing a predefined protocol, and structured the report according to PRISMA (Preferred Reporting Items for Systematic reviews and Meta-Analyses) guidelines [30].

To identify relevant publications, we established a uniform strategy for searching MEDLINE, Embase, CINAHL, PsycInfo, Web of Science, and grey literature including Dissertation and Theses Databases, CADTH, Health Canada, CIHI, and CMA Infobase, following the guidance of a medical librarian [31]. Furthermore, we manually searched reference lists of all included studies, related systematic reviews, and all additional relevant reviews identified in the electronic search. We also contacted authors of key publications and identified relevant 
conference abstracts, and reviewed personal libraries of the research team [32-35]. We systematically searched terms relevant to PDMPs, matching terms against possible subject headings (e.g. MeSH) and keywords. We performed the search on January 22, 2018 and included all pertinent publications published prior to that date (see Additional file 1).

\section{Risk of bias assessment}

We assessed potential risk of bias for each study meeting selection criteria using the Quality of Prognostic Studies (QUIPS) tool. The QUIPS tool assesses risk of bias across six domains: study participation, study attrition, prognostic factor measurement, outcome measurement, study confounding, statistical analysis and reporting [36]. Specifically, we considered low risk of bias for the study sample if the response rate was $>=70 \%$ participation, moderate for $60-69.9 \%$, and high for $<60 \%$. Further, we considered whether studies adjusted for the following potential confounders: (a) The characteristics/features of PDMP (i.e. mandatory use), (b) demographic characteristics of sample (either individual, physician or jurisdiction level), and (c) presence of other related interventions in the study period (or other trends in substance use). Studies adjusting for at least two confounders were considered to have a low risk of bias on study confounding, 1 would be moderate, and 0 would be high.

\section{Data extraction, synthesis, and analysis}

For all included studies, data extraction was completed by two independent reviewers using pre-tested data extraction forms developed in Covidence [29]. Any discrepancies in data extraction were discussed and the assessment of a third reviewer was sought for resolution. We extracted relevant study details (i.e. authors, year, jurisdiction, study design, sample size), population characteristics (i.e. providers, patients), interventions (i.e. included PDMP characteristics), and data sources (i.e. administrative, survey). Outcomes extracted included any unadjusted and adjusted associations between the presence of a PDMP, or the change in PDMP states and non-PDMP states over time, and each opioid-related harm or consequence outcome, as well as all variables controlled for.

We synthesized our data narratively. If studies had overlapping datasets, years of data, and jurisdictions, the study with most years of data for a dataset and jurisdiction was designated as the primary study in our narrative synthesis and the remaining studies were secondary. If a study presented both unadjusted and adjusted data, both were extracted; however, the adjusted data was included in our primary synthesis.
We used Excel 2016 for data management and Stata 15 for descriptive analyses and calculating pooled estimates $[37,38]$.

\section{Results}

The study selection process for this review is summarized in the PRISMA flow chart presented in Fig. 1. A total of 161 articles were assessed at the full text level, resulting in the inclusion of 22 studies addressing the association of PDMP status with opioid-related consequences or harms. All included studies took place in the United States and 72.7\% presented findings among the general population (Table 1). Studies were published between 2006 and 2018 and include data years from 1992 to 2014. Twelve datasets were used, with the Treatment Episode Data Set (TEDS) being the most common, appearing in six publications with treatment admission outcomes. Studies with overlapping data differed in the years of data covered. Opioidrelated consequences and harms are described in detail below and separated into the following four categories: illicit and problematic opioid use, opioid-related care outcomes, opioid-related adverse outcomes, and opioidrelated legal and criminal outcomes.

\section{Illicit and problematic opioid use}

Two studies reported an association between PDMP status and heroin use, both using the same dataset and presenting adjusted models [24, 28]. These studies drew on multiple years of cross-sectional survey data, using an interrupted time series analysis that captured data from 36 states from 2004 to 2014 [24]. Neither study found any significant associations between PDMP status and heroin use. One study also examined the association between past-year opioid dependence and PDMP status; no significant association was observed [24]. See Additional file 2: Table S1 for individual study details.

\section{Opioid-related care outcomes}

Eight studies examined the association between PDMP status and opioid-related care outcomes [19, 25, 27, 39-44]. One study, using CDC WONDER, SID, and SEDD data sets, reported on inpatient discharges in two jurisdictions with PDMPs from 2009 to 2012 using a difference-in-difference approach and found no change in the rate of discharges related to prescription opioids, and a slight increase in discharges related to heroin $(\beta=0.014,90 \%$ CI $[0.001-0.027])$ post PDMP implementation in adjusted models [40]. That same study, along with an interrupted time series study on nine states from 2004 to 2011 using the DAWN data set, found no statistically significant associations when examining emergency department visits for all prescription opioids, Schedule II opioids, and heroin over time when comparing PDMP jurisdictions to non PDMP jurisdictions $[25,40]$. 


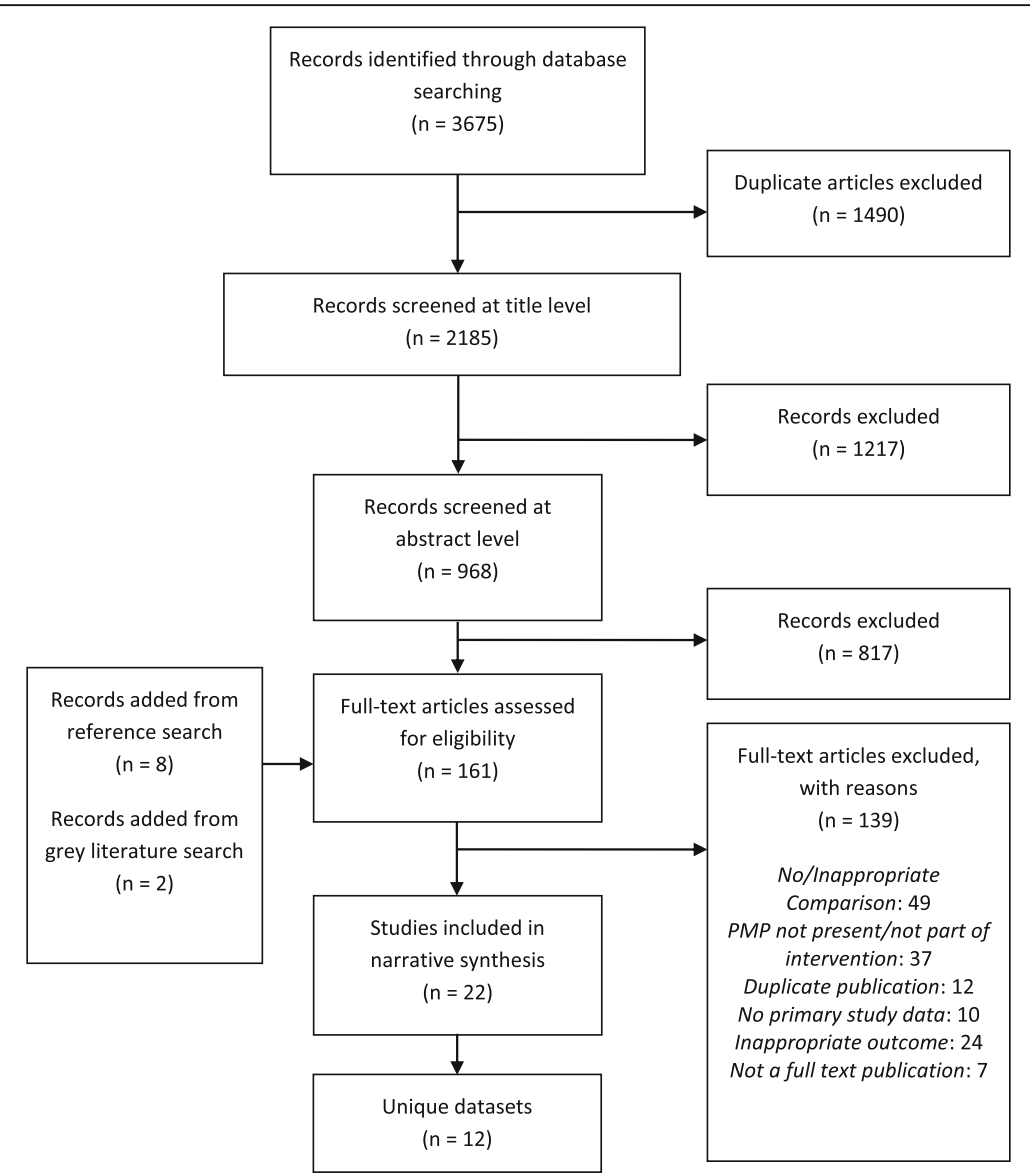

Fig. 1 PRISMA flow chart depicting the study selection and inclusion process and results

Seven studies described opioid-related treatment admissions. Six of the seven used the TEDS dataset, while Reifler et al. used the RADARS dataset [19, 27, 39, 41-44]. Branham et al. covered the most years of data from TEDS; they found no association when examining the association between treatment admissions for heroin and PDMP status [27]. Branham et al. and Reifler et al. found no association between PDMP status and prescription opioid treatment admissions [27, 42]. In Branham et al.'s secondary analysis, they examined each of the states that implemented a PDMP during the study period (1992-2012) separately. They found that 13 out of 22 states saw a significant change in the average heroin admissions post PDMP - 10 states saw more admissions and three saw fewer. Furthermore, 11 US states reported a significant increase in average prescription opioid treatment admissions post-PDMP implementation [27]. See Additional file 2: Table S2 for individual study details.

\section{Opioid-related adverse events}

Thirteen studies reported on opioid-related adverse events [39, 40, 42, 43, 45-53]. Of those studies, 10 reported on fatal opioid overdoses, with overlapping datasets in multiple studies [39, 40, 43, 45-47, 50, 51, 53, 54]. Four studies reported on heroin-related overdose deaths, none of which found any association with PDMP status in adjusted models [39, 40, 50, 53].

Six studies reported on overdose deaths related to both prescription and non-prescription opioids from two unique data sources - CDC WONDER and NVSS [39, 43, $45,47,50-52]$. Both primary studies (with the most years of data available) reported no significant associations between opioid-related deaths and PDMP status $[43,45]$.

Five studies reported on fatal prescription opioid overdoses using three unique data sources - CDC WONDER, NVSS and state-specific inpatient and emergency databases [40, 45-47, 53]. No significant association between PDMP status and fatal prescription opioid overdose deaths was observed in adjusted models in any of these studies [40, 45, 46, 53].

Two studies reported on the association between specific opioid-related deaths and PDMP status [45, 50]. Nam et al. performed an interrupted time series analysis on data from 19 states that implemented PDMPs from 1999 to 2014 and found no association between methadone-related overdoses and PDMP status over 


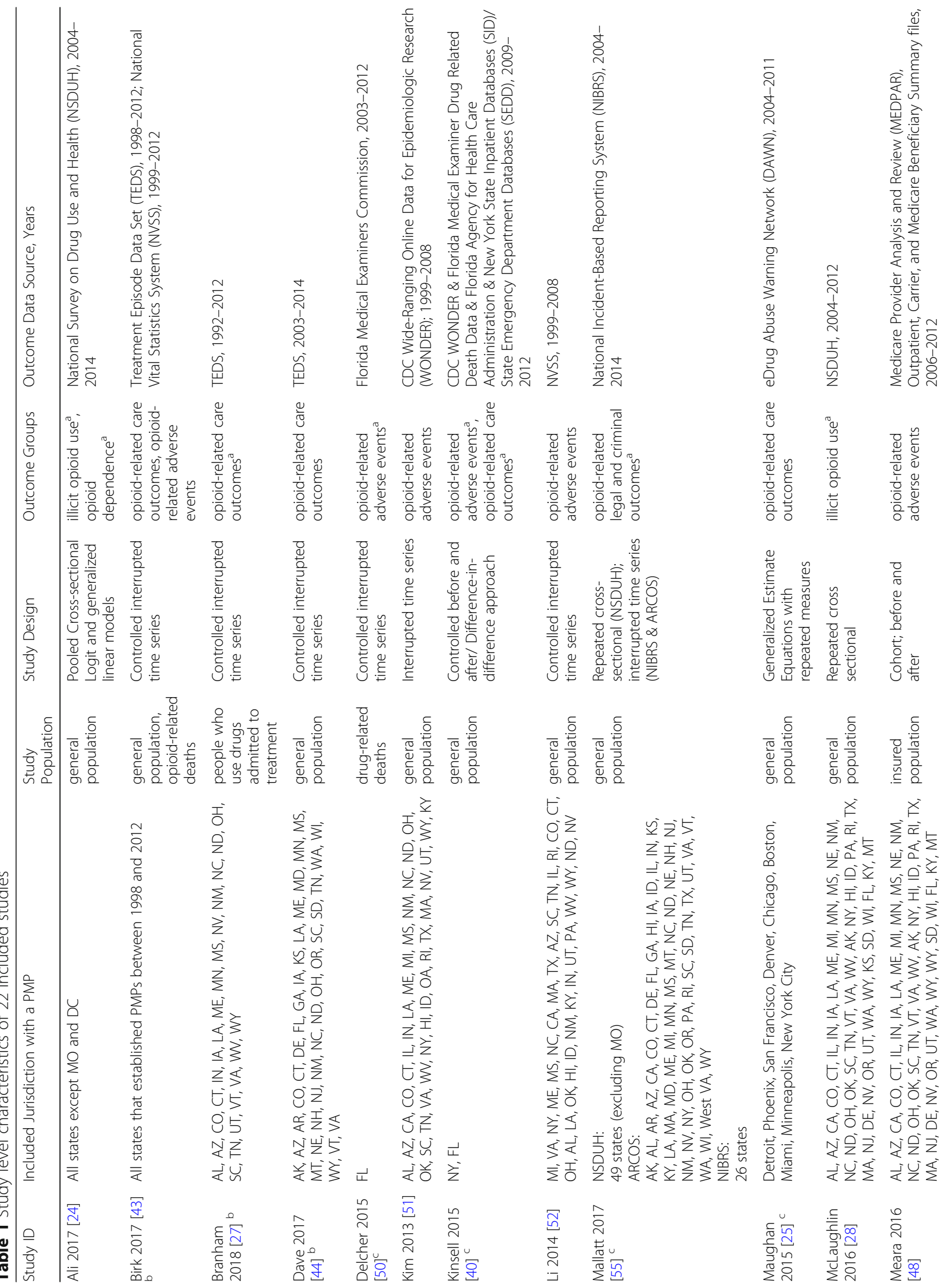




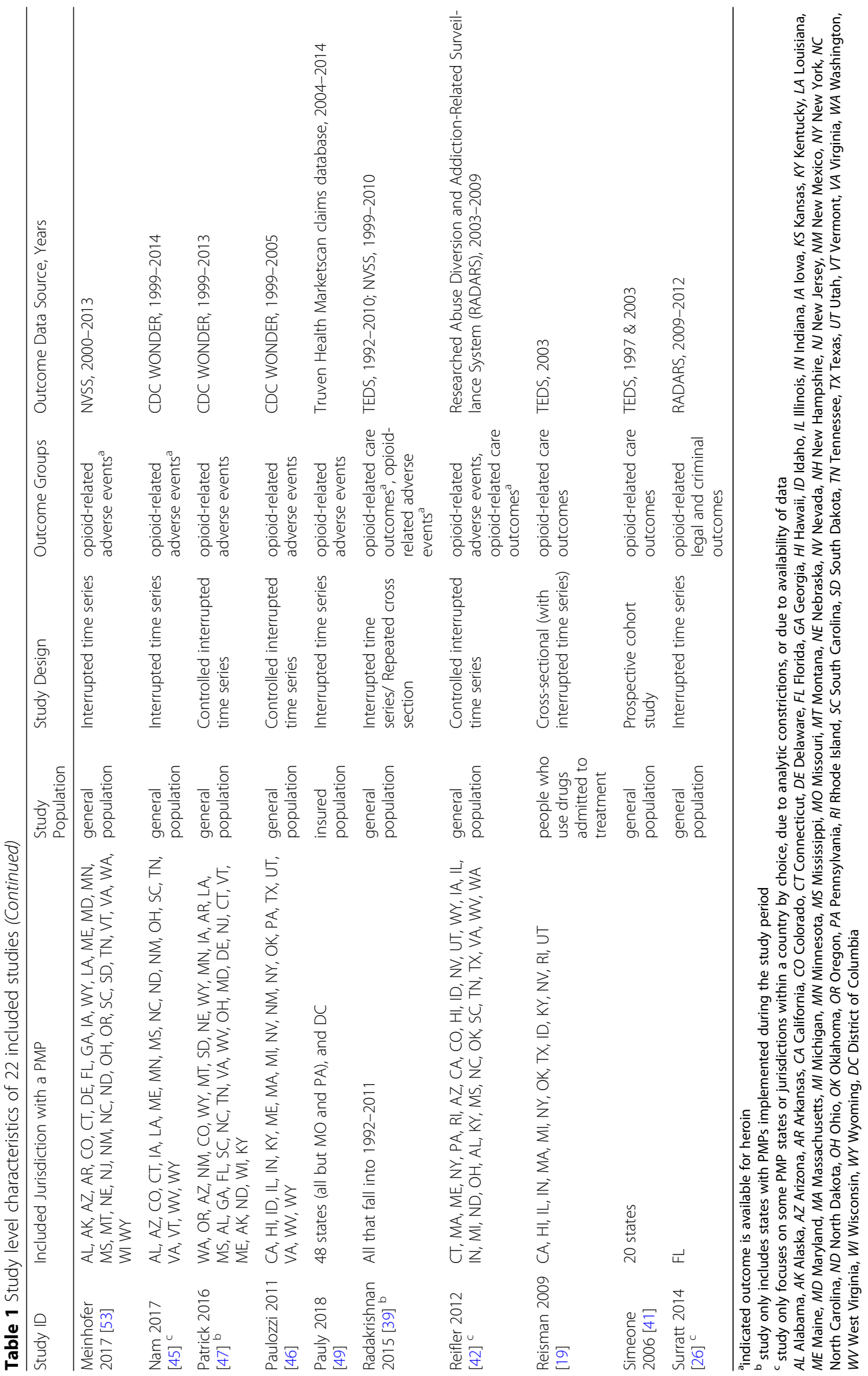


time [45]. Delcher et al. performed a controlled interrupted time series analysis from 2003 to 2012 and observed a significant decline in oxycodone-caused overdoses in Florida post-PDMP implementation $(p=0.0079)$, but not in nonoxycodone related overdoses [50].

Two unique studies examined the association between non-fatal overdose and PDMPs [48, 49]. A study examining cohorts of Medicare beneficiaries for each year from 2006 to 2012 in 45 states found no association between PDMP status and the proportion of insurance beneficiaries experiencing non-fatal prescription opioid overdoses in adjusted models [48]. The second study was an interrupted time series of 49 state PDMPs from 2004 to 2014 and found that at baseline (2004), prescription opioid poisoning rates were higher in PDMP states than non PDMP states; however, the rate of prescription opioid poisonings over time decreased more quickly in PDMP states than in non PDMP states $(\beta=-0.005,95 \%$ CI [-0.008- -0.003]) [49]. Similarly, a separate study reported on intentional opioid poisonings for five drugs combined (fentanyl, hydromorphone, methadone, morphine, and oxycodone) and observed that, while rates were higher in PDMP states at baseline, rates reduced at a greater rate per quarter for PDMP states compared to non-PDMP states [42]. See Additional file 2: Table S3 for individual study details.

\section{Opioid-related legal and criminal outcomes}

Two unique studies reported on three types of opioidrelated criminal outcomes: crime rates, identification of potential dealers, and opioid diversion $[26,55]$. Employing standardized, adjusted difference in difference models, no association was found between PDMP status and opioid-related crime rates or the identification of potential opioid dealers [55]. As for diversion, an interrupted time series study from 2009 to 2012 found significant reductions in rates of diversion of oxycodone, methadone, and morphine in over time in Florida postPDMP implementation [26]. Finally, no significant trends were identified for other measured drugs in this study (fentanyl, hydrocodone, hydromorphone, buprenorphine, and tramadol). See Additional file 2: Table S4 for individual study details.

\section{Risk of Bias assessment}

A detailed description of risk of bias assessment across the six QUIPs domains by study and overall can be found in Table 2. Overall, study quality was good; a low risk of bias rating was given for $81.8 \%$ of studies on study participation, $100.0 \%$ on study attrition, $45.5 \%$ on PDMP measurement, $54.5 \%$ on outcome measurement, $68.3 \%$ on study confounding, and $81.8 \%$ statistical analysis and reporting. Nine of the included studies were not published in peer- reviewed journals (i.e. working papers, theses) [28, 39-41, $43,44,51,53,55]$. While this does not necessarily indicate poor study quality, it does indicate that the results should be interpreted with caution as these studies have not undergone a rigorous peer review.

\section{Discussion}

In this systematic review we sought to identify associations between PDMP status and opioid-related consequences and harms. Twenty-two publications from 12 unique data sets were analysed. Overall, we did not find evidence to indicate that PDMPs were effective in reducing several types of population-level consequences and harms including illicit opioid use, opioid dependence, ED visits, or inpatient discharges. There were, however, very few studies that measured each of these outcomes.

In individual studies, rates of fatal and non-fatal overdoses were higher at baseline in PDMP states, but reductions were observed after PDMP implementation; however, the relationship overall was less clear. Conflicting evidence was found for the association between treatment admissions and PDMP status, with some studies indicating an increase in admissions, and others finding a decrease. An increase in treatment admissions is not necessarily a poor outcome and could be indicative of more people seeking treatment (rather than more people using opioids) due to intervention from PDMP findings, or other arms of opioid related intervention strategies.

While there were no observed effects for the association of PDMPs with harms and consequences related to opioids, PDMPs, if properly operationalized, can be an important piece of a broader opioid strategy. They may work in tandem with other arms of an opioid strategy, rather than functioning as standalone programs. Many studies did not control for the presence and timing of other interventions in their statistical models, which may have masked estimation of the true effect of PDMPs on opioid-related harms. Equally important, in order for PDMPs to function optimally, healthcare providers must use the data whenever they are prescribing an opioid [56]. A recent evidence synthesis by our team found that only $57 \%$ of healthcare providers had ever used PDMP data to inform their prescribing decisions (using data from 26 studies), and fewer than 1 in 5 used a PDMP with each prescription. Interventions aimed at increasing PDMP utilization among healthcare providers would impact opioid-related harms and outcomes over time. None of the included studies considered PDMP utilization by healthcare providers when estimating the effect of PDMPs on outcomes.

While only two studies received a rating of high risk of bias on any domain, there were some areas of concern including study confounding, PDMP implementation, and outcome measurement. A study was rated high risk 
Table 2 Detailed risk of bias and quality assessment using the QUIPs tool

\begin{tabular}{|c|c|c|c|c|c|c|}
\hline Study & $\begin{array}{l}\text { Study } \\
\text { participation }\end{array}$ & $\begin{array}{l}\text { Study } \\
\text { attrition }\end{array}$ & $\begin{array}{l}\text { PMP } \\
\text { measurement }\end{array}$ & $\begin{array}{l}\text { Outcome } \\
\text { measurement }\end{array}$ & $\begin{array}{l}\text { Study } \\
\text { confounding }\end{array}$ & $\begin{array}{l}\text { Statistical analysis and } \\
\text { reporting }\end{array}$ \\
\hline Ali 2017 [24] & moderate & low & moderate & moderate & low & low \\
\hline Birk 2017 [43] & low & low & moderate & low & low & low \\
\hline Branham 2018 [27] & moderate & low & moderate & low & low & low \\
\hline Dave 2017 [44] & low & low & moderate & moderate & low & low \\
\hline Delcher 2015 [50] & low & low & low & low & low & moderate \\
\hline Kim 2013 [ 51] & low & low & moderate & moderate & low & low \\
\hline Kinsell 2015 [ 40] & low & low & low & low & low & moderate \\
\hline Li 2014 [ 52] & low & low & low & low & low & low \\
\hline Maughan 2015 [ 25] & low & low & low & low & low & low \\
\hline Mallatt 2017 [ 55] & low & low & low & low & low & low \\
\hline McLaughlin 2016 [ 28] & moderate & low & moderate & moderate & low & low \\
\hline Meara 2016 [ 48] & low & low & moderate & moderate & low & low \\
\hline Meinhofer 2017 [ 53] & moderate & low & low & low & high & low \\
\hline Nam 2017 [ 45] & low & low & moderate & moderate & low & low \\
\hline Patrick 2016 [ 47] & low & low & moderate & moderate & moderate & low \\
\hline Paulozzi 2011 [ 46] & low & low & moderate & moderate & moderate & low \\
\hline Pauly 2018 [ 49] & low & low & low & low & low & low \\
\hline Radakrishnan 2015 [ 39] & low & low & moderate & moderate & low & low \\
\hline Reifler 2012 [ 42] & low & low & low & low & moderate & low \\
\hline Reisman 2009 [ 19] & low & low & low & low & moderate & moderate \\
\hline Simeone 2006 [ 41] & low & low & moderate & moderate & high & high \\
\hline Surratt 2014 [ 26] & low & low & low & low & moderate & low \\
\hline Overall \% low & $81.8 \%$ & $100.0 \%$ & $45.5 \%$ & $54.5 \%$ & $68.2 \%$ & $81.8 \%$ \\
\hline Overall \% moderate & $18.2 \%$ & $0.0 \%$ & $54.5 \%$ & $45.5 \%$ & $22.7 \%$ & $13.6 \%$ \\
\hline Overall \% high & $0.0 \%$ & $0.0 \%$ & $0.0 \%$ & $0.0 \%$ & $9.1 \%$ & $4.6 \%$ \\
\hline
\end{tabular}

of bias on the study confounding domain if there was no evidence of accounting for important confounders (including demographic trends, other opioid-related interventions in the jurisdiction, time trends, and features of PDMPs) in the study design or statistical models. Concerns with bias on PDMP/outcome measurement mainly stemmed from the timing of measurement. Measuring exposure or outcome only on an annual basis raised concerns about potential misclassification of PDMP status for outcomes during that year (i.e. a prescription could have been dispensed before a PDMP was implemented, but still marked as occurring during a year where the state had a PDMP). Studies that accounted for PDMP status more frequently (i.e. monthly or quarterly) raised less concerns about misclassification. As the body of evidence evolves, a systematic review should be performed focusing on features of PDMPs, such as mandatory use, and potential relationships with opioidrelated harms and consequences. More primary studies are required for certain outcomes of interest, including hospital visits, crime and illicit opioid use.
The last year of data covered by the studies captured in this review was 2014. We need more recent and robust data as the opioid crisis has drastically evolved since then, with more recent focus on the very potent fentanyl. Finally, all studies included in this review were conducted in the United States. Future research should seek to determine the impact of PDMPs on opioidrelated consequences and harms in other countries.

\section{Limitations and strengths of the study}

This was a rigorously conducted systematic review that synthesized all studies related to the effectiveness of PDMP status in reducing opioid-related harms and consequences. A thorough evaluation of the literature was executed, and the quality of each included study was reviewed to identify any potential biases. We also considered a broad range of patient safety outcomes such as overdose and hospital admissions.

In terms of limitations, we were unable to perform meta-analyses due to heterogeneity across studies and outcomes. Included studies varied in how they measured 
associations and employed different units of analysis (i.e. person years, state years, states, etc.), populations (i.e. general, insured, treatment, etc.), covariate adjustments, and most importantly, analytic approach. Many studies included in this review used data from TEDS. States contributing data to TEDS can collect either publicallyor privately-funded admissions [57]. This variability limits TEDS in its ability to assess admissions outcomes. Additionally, our search was completed in early 2018 and new studies may have been completed. To address this, a single database scan (Ovid MEDLINE) of the literature for 2018 and 2019 was completed by two reviewers (MW and MA) and identified only one potentially relevant study [58]. This well-designed study provides support for the effectiveness of PDMPs, finding that jurisdictions with online PDMPs observed significant reductions in rates of opioid-related hospitalizations.

The objective of this systematic review was to examine the effect of PDMP implementation (initial and over time) on opioid-related harms and consequences. As such, we did not explore outcomes related to other monitored drugs such as benzodiazepines, which may also be affected by PDMP implementation. Furthermore, although some studies accounted for PDMP features, this review did not focus on differences across types of PDMPs or on the effect of legislative changes to PDMP characteristics in regions with pre-existing PDMPs (e.g. mandatory utilization) given the small number of studies for most outcomes of interest.

\section{Conclusions}

Although we did not find evidence to strongly support the overall effectiveness of PDMPs in reducing opioid-related consequences and harms, if operationalized appropriately, they remain a valuable piece of a broader strategy to combat the opioid crisis. The mere presence of PDMPs is a reminder to physicians that they need to be careful when prescribing opioids. PDMPs may not necessarily address the root causes of addiction or guide patients directly to treatment options; however, they can be an important tool for minimizing potential harm and should work in tandem with other opioid preventation programs.

\section{Additional files}

Additional file 1. Search Strategy.

Additional file 2: Table S1. Illicit and problematic opioid use. Table S2. Opioid-related care outcomes. Table S3. Opioid-related adverse events. Table S4. Opioid-related legal and crime outcomes.

\section{Abbreviations}

CADTH: Canadian Agency for Drugs and Technologies in Health; CDC WONDER: Centers for Disease Control and prevention Wide-ranging ONline Data for Epidemiologic Research; CIHI: Canadian Institute for Health Information; CINAHL: Cumulative Index to Nursing \& Allied Health Literature;
CMA: Canadian Medical Association; ED: Emergency Department; MeSH: Medical Subject Headings; NVSS: National Vital Statistics System; OUD: Opioid Use Disorder; PDMP: Prescription Drug Monitoring Program; PRISMA: Preferred Reporting Items for Systematic reviews and Meta-Analyses; QUIPS: QUality In Prognosis Studies; RADARS: Researched Abuse Diversion and Addiction-Related Surveillance system; RCT: Randomized Controlled Trial; SEDD: State Emergency Department Databases; SID: State Inpatient

Databases; TEDS: Treatment Episode Data Set

\section{Acknowledgements}

We would like to acknowledge Leah Boulos for her work in developing the search strategy, and guidance in systematic review methods.

\section{Authors' contributions}

$M A, J H$, and MW designed the study. ER and MW conducted the systematic review and analysed the data with help from AR and MA. ER wrote the manuscript, and then MA, JH, and MW critically revised it before all authors read and approved the final version. All authors have read and approved the manuscript.

\section{Funding}

This research was funded by the Canadian Institutes of Health Research Operating Grant: Opioid Crisis Knowledge Synthesis/Subvention (\#397982). The funder had no role in the design of the study, data collection, data analysis, data interpretation, nor in the writing of the manuscript.

Availability of data and materials

Not applicable.

Ethics approval and consent to participate

Not applicable.

Consent for publication

Not applicable.

\section{Competing interests}

The authors declare that they have no competing interests.

Received: 9 April 2019 Accepted: 15 October 2019

Published online: 01 November 2019

\section{References}

1. Jones CM, Campopiano M, Baldwin G, Mccance-Katz E. National and state treatment need and capacity for opioid agonist medication-assisted treatment. Am J Public Health. 2015;105(8):e55-64 Available from: https:// ajph.aphapublications.org/doi/10.2105/AJPH.2015.302664

2. Dhalla IA, Persaud N, Juurlink DN. Facing up to the prescription opioid crisis. BMJ. 2011;343:1-5 Available from: https://doi.org/10.1136/bmj.d5142.

3. Rummans TA, Burton MC, Dawson NL. How good intentions contributed to bad. Mayo Clin Proc. 2018;93(3):344-50 Available from: https://doi.org/10. 1016/j.mayocp.2017.12.020, Mayo Foundation for Medical Education and Research.

4. National Drugs Technical Report: Estimated world requirements for 2013: statistics for 2011 [internet]. 2012. Available from: https://www.incb.org/ incb/en/narcotic-drugs/Technical_Reports/2012/narcotic-drugs-technicalreport_2012.html

5. Brat GA, Agniel D, Beam A, Yorkgitis B, Bicket M, Homer M, et al. Postsurgical prescriptions for opioid naive patients and a ssociation with overdose and misuse : retrospective cohort study. BMJ. 2018;360:1-9 Available from: https://doi.org/10.1136.bmj.j5790.

6. Imtiaz S, Shield KD, Fischer B, Rehm J. Harms of prescription opioid use in the United States. Subst Abuse Treat Prev Policy. 2014;9(43):1-5 Available from: https://doi.org/10.1186/1747-597X-9-43.

7. Bohnert A, Valenstein M, Bair MJ, Ganoczy D, Mccarthy JF, Ilgen MA, et al. Association between opioid prescribing patterns and opioid overdoserelated deaths. JAMA. 2011;305(13):1315-21 Available from: https://doi.org/ 10.1001/jama.2011.370.

8. Dunn K, Saunders K, Rutter C, Al E. Overdose and prescribed opioids: associations among chronic non-cancer pain patients, Ann Intern Med. 2010;152(2):85-92 Available from: https://doi.org/10.1059/0003-4819-152-2201001190-00006. 
9. Borwein A, Kephart G, Whelan E, Asbridge M. Prescribing Practices Amid the OxyContin Crisis: Examining the Effect of Print Media Coverage on Opioid Prescribing Among Physicians. J Pain. 2013;14(12):1686-93.e1 Available from: https://doi.org/10.1016/j.jpain.2013.08.012, Elsevier Ltd.

10. Fischer B, Rehm J. Deaths related to the use of prescription opioids. CMAJ. 2009;181(12):881-2 Available from: https://doi.org/10.1503/cmaj.091791.

11. Hansen RN, Oster G, Edelsberg J, Woody GE, Sullivan SD. Economic costs of nonmedical use of Prescription opioids. Clin J Pain. 2011;27(3):194-202 Available from: https://doi.org/10.1097/AJP.0b013e3181ff04ca.

12. Prescription SB. Monitoring Programs in Canada: Best Practice and Program [Internet]. In: Canadian Centre on Substance Abuse; 2015. p. 209-10. Available from: https://doi.org/10.1016/j.drugalcdep.2015.07.565

13. Furlan AD, Frcpc PM, Pellerin D, Shaw K, Bsp DS, Wilson G, et al. Overview of four prescription monitoring / review programs in Canada. Pain Res Manag. 2014;19(2):102-6 Available from: https://doi.org/1918-1523.

14. Brandeis University. Technical assistance guide: history of Prescription drug monitoring programs [internet]. 2018. Available from: https://www. pdmpassist.org/pdf/PDMP_admin/TAG_History_PDMPs_final_20180314.pdf

15. Egan JE, Casadonte P, Gartenmann T, Martin J, Mccance-katz EF, Netherland J, et al. The physician clinical support system-buprenorphine ( PCSS-B ): a novel project to expand / improve buprenorphine treatment. J Gen Intern Med. 2010;25(9):936-41 Available from: https:/doi.org/10.1007/s11606-010-1377-y.

16. Devonshire $E_{1}$ Nicholas MK. Continuing education in pain management : using a competency framework to guide professional development. Pain reports. 2018;3(5):1-7 Available from: https://doi.org/10.1097/PR9. 0000000000000688 .

17. Eggertson L. Take-home naloxone kits preventing overdose deaths. CMAJ. 2014;186(1) Available from: https://doi.org/10.1503/cmaj.109-4663.

18. Ashburn MA. The evolution of prescription drug monitoring programs. Pharmacoepidemiol Drug Saf. 2016;25:852-853. Available from: https://doi. org/10.1002/pds.4036.

19. Reisman RM, Shenoy PJ, Atherly AJ, Flowers CR. Prescription opioid usage and Abuse relationships : an evaluation of state Prescription drug monitoring program efficacy. Subst Abus Res Treat. 2009:3:41-51.

20. State Profiles [Internet]. 2018. Available from: https://www.pdmpassist.org/ content/state-profiles

21. Maryland Department of Health. Maryland Advisory Council on Prescription Drug Monitoring Legislative Report. Baltimore, MD; 2009.

22. Finley EP, Garcia A, Rosen K, Mcgeary D, Pugh MJ, Potter JS. Evaluating the impact of prescription drug monitoring program implementation : a scoping review. BMC Health Serv Res. 2017;17(420):1-8 Available from: https://doi.org/10.1186/s12913-017-2354-5.

23. Fink DS, Schleimer JP, Sarvet A, Grover KK, Delcher C, Castillo-carniglia A, et al. Association between Prescription drug monitoring programs and nonfatal and fatal drug overdoses a systematic review. Ann Intern Med. 2018;168(11):783-90 Available from: https://doi.org/10.7326/M17-3074.

24. Ali MM, Dowd WN, Classen T, Mutter R, Novak SP. Addictive Behaviors Prescription drug monitoring programs, nonmedical use of prescription drugs, and heroin use : Evidence from the National Survey of Drug Use and Health. Addict Behav. Elsevier Ltd; 2017;69:65-77. Available from: https://doi.org/10.1016/j.addbeh.2017.01.011

25. Maughan BC, Bachhuber MA, Mitra N, Starrels JL. Prescription monitoring programs and emergency department visits involving opioids , 2004-2011. Drug Alcohol Depend, Available from: https://doi.org/10.1016/j.drugalcdep. 2015.09.024, Elsevier Ireland Ltd. 2015;156(January):282-8.

26. Surratt HL, Grady CO, Kurtz SP, Stivers Y, Cicero TJ, Dart RC, et al. Reductions in prescription opioid diversion following recent legislative interventions in Florida. Pharmacoepidemiol Drug Saf. 2014;23:314-20 Available from: https://doi.org/10.1002/pds.3553.

27. Branham DK. Time-series analysis of the impact of Prescription drug monitoring programs on heroin treatment admissions time-series analysis of the impact of Prescription drug monitoring programs on heroin treatment admissions. Subst Use Misuse. 2018;53(4):694-701 Available from: https://doi.org/10.1080/10826084.2017.1363232, Taylor \& Francis.

28. McLaughlin S Empirical Essays to inform marijuana legalization and Prescription opioid Abuse policy [internet]. 2016. Available from: http:// search.proquest.com/docview/1923434357/

29. Veritas Health Innovation. Covidence Systematic Review Software. 2017.

30. PRISMA. PRISMA: Transparent Reporting of Systematic Reviews and MetaAnalyses [Internet]. 2015 [cited 2019 Jan 29]. Available from: http://prismastatement.org/prismastatement/Checklist.aspx
31. Higgins J, Green S. Cochrane handbook for systematic reviews for interventions. The Cochra. West Sussex, England: John Wiley \& Sons Ltd.; 2008.

32. Fleming M, Barner J, Bamgbade. Mortality rate comparison between states with and without prescription drug monitoring programs and association federal costs [Abstract]. Value Health. 2010;13(3):A93.

33. Menchine M, Georgis M, Lam C, Seabury S. Do state prescription drug monitoring programs reduce opioid consumption? [abstract]. Ann Emerg Med. 2016;68(4):S79 Available from: https://doi.org/10.1016/j.annemergmed. 2016.08.216.

34. Miller D, Miller L, Franger S. Reduction of opioid and illicit drug abuse after initiation of state electronic prescription monitoring program [abstract]. Pain Med. 2009;10(1):275-6.

35. Painter J. Effect of prescription monitoring programs (PMP's) on opioid overdose admission [abstract]. Value Health. 2011;14(3):A197-8 Available from: https://doi.org/10.1016/j.jval.2011.02.1089.

36. Hayden JA, Van Der Windt DA, Cartwright $J$, Co P. Research and reporting methods annals of internal medicine Assessing Bias in studies of prognostic factors. Ann Intern Med. 2013;158:280-6.

37. Microsoft. Excel. 2016

38. StataCorp. Stata 15. 2017.

39. Radakrishnan S, ESSAYS IN. THE ECONOMICS OF RISKY HEALTH BEHAVIORS [Internet]: Cornell University; 2015. Available from: http://search.proquest. com/docview/1661461833/

40. Kinsell H, ASSESSING THE, EFFECTS OF. FLORIDA ' S ANTI -PILL MILL LAW ON PRESCRIPTION DRUG RELATED HEALTH OUTCOMES [Internet]: University of Florida; 2015. Available from: http://search.proquest.com/docview/172 7613694/

41. Simeone R, Holland L. An Evaluation of Prescription Drug Monitoring Programs. 2006;12210(2005).

42. Reifler LM, Droz D, Bailey JE, Schnoll SH, Fant R, Dart RC, et al. State trends in opioid Abuse / misuse ? Pain Med. 2012;13:434-42 Available from: https://doi.org/10.1111/j.1526-4637.2012.01327.x.

43. Birk $E$, Waddell $G$. The mitigating role of Prescription drug monitoring programs in the Abuse of Prescription drugs. IZA Inst Labor Econ. 2017;10990:1-42.

44. Dave DM, Grecu AM, Saffer H. MANDATORY ACCESS PRESCRIPTION DRUG MONITORING PROGRAMS AND PRESCRIPTION DRUG ABUSE [Internet]. Cambridge: MA; 2017. Available from: http://www.nber.org/papers/w23537

45. Nam YH, Shea DG, Shi Y, Moran JR. State Prescription drug monitoring programs and fatal drug overdoses. Am J Manag Care. 2017;23(5):297-303.

46. Paulozzi LJ, Kilbourne EM, Desai HA, Sci MM, Church F, Hamilton BA. Prescription drug monitoring programs and death rates from drug overdose. Pain. 2011;12:747-54 Available from: https://doi.org/10.1111/j. 1526-4637.2011.01062.x.

47. Patrick SW, Fry CE, JT F, Buntin MB. Implementation of Prescription drug monitoring programs associated with reductions in opioid- related death rates. Health Aff. 2016;35(7):1324-32 Available from: https://doi.org/10.1377/ hlthaff.2015.1496.

48. Meara E, Horwitz JR, Powell W, McClelland L, Zhou W, O'Malley AJ, et al. State legal restrictions and Prescription- opioid use among disabled adults. N Engl J Med. 2016;375:44-53 Available from: https://doi.org/10.1056/ NEJMsa1514387.

49. Pauly NJ, Slavova S, Delcher C, Freeman PR, Talbert J. Features of prescription drug monitoring programs associated with reduced rates of prescription opioid-related poisonings. Drug Alcohol Depend. 2018;184:2632. Available from: https://doi.org/10.1016/j.drugalcdep.2017.12.002. Elsevier

50. Delcher C, Wagenaar AC, Goldberger BA, Cook RL, Maldonado-molina MM. Abrupt decline in oxycodone-caused mortality after implementation of Florida's Prescription drug monitoring program. Drug Alcohol Depend. 2015;150:63-8 Available from: https://doi.org/10.1016/j.drugalcdep.2015.02. 010, Elsevier Ireland Ltd.

51. Kim M. THE IMPACT OF PRESCRIPTION DRUG MONITORING PROGRAMS ON OPIOID-RELATED POISONING DEATHS [Internet]: Johns Hopkins University; 2013. Available from: http://search.proquest.com/docview/1432503368/

52. Li G, Brady JE, Lang BH, Giglio J, Wunsch H, Dimaggio C. Prescription drug monitoring and drug overdose mortality. Inj Epidemiol. 2014;1:1-8 Available from: https://doi.org/10.1186/2197-1714-1-9.

53. Meinhofer A. Prescription drug monitoring programs : the role of asymmetric information on drug availability and Abuse; 2017. p. 1-48. Available from: https://doi.org/10.1162/ajhe_a_00101

54. Lin DH, Lucas E, Murimi IB, Jackson K, Baier M, Frattaroli S, et al. Physician attitudes and experiences with Maryland 's prescription drug monitoring 
program ( PDMP ). Addiction. 2016;112:311-9 Available from: https://doi. org/10.1111/add.13620.

55. Mallatt J. The Effect of Prescription Drug Monitoring Programs on Opioid Prescriptions and Heroin Crime Rates. 2017. Report No.: 1292.

56. Asbridge M, Hayden J, Campbell S, Wilson M, Macdougall P. Utilization and effectiveness of Prescription monitoring programs : a systematic review (CIHR Report). Halifax: In Press; 2018.

57. Substance Abuse \& Mental Health Data Archive. Treatment Episode Data Set: Admissions (TEDS-A) [Internet]. Available from: https://www.datafiles. samhsa.gov/study-series/treatment-episode-data-set-admissions-tedsnid13518

58. Castillo-Carniglia A, Ponicki WR, Gaidus A, Gruenewald PJ, Marshall BD, Fink DS, Martins SS, Rivera-Aguirre A, Wintemute GJ, Cerdá M. Prescription drug monitoring programs and opioid overdoses: exploring sources of heterogeneity. Epidemiology. 2019 Mar 1;30(2):212-20.

\section{Publisher's Note}

Springer Nature remains neutral with regard to jurisdictional claims in published maps and institutional affiliations.

Ready to submit your research? Choose BMC and benefit from:

- fast, convenient online submission

- thorough peer review by experienced researchers in your field

- rapid publication on acceptance

- support for research data, including large and complex data types

- gold Open Access which fosters wider collaboration and increased citations

- maximum visibility for your research: over $100 \mathrm{M}$ website views per year

At BMC, research is always in progress.

Learn more biomedcentral.com/submissions 